\title{
Alcohol in Canada: reducing the toll through focused interventions and public health policies
}

\author{
Norman Giesbrecht PhD, Timothy Stockwell PhD, Perry Kendall MB MSc, Robert Strang MD MHSc, \\ Gerald Thomas PhD
}

Competing interests: See end of article for competing interests.

This article has been peer reviewed.

Correspondence to: Dr. Norman A. Giesbrecht, norman_giesbrecht @ camh.net

CMAJ 2011. DOI:10.1503 /cmaj.100825
I n high-income countries like Canada, alcohol consumption ranks second (behind tobacco use) as an etiologic risk factor in the World Health Organization (WHO) burden of disease studies. ${ }^{1,2}$ Based on 2002 data, the estimated annual cost in Canada for health care directly related to alcohol consumption was $\$ 3.3$ billion, and the total direct and indirect cost was $\$ 14.6$ billion, compared with $\$ 17$ billion related to tobacco and $\$ 8.2$ billion related to illicit drugs. ${ }^{3}$

Several critical developments point to a likely increase in the already high disease burden from alcohol in Canada. Overall per capita sales have been rising since $1996,{ }^{4}$ from $7.2 \mathrm{~L}$ of pure alcohol in 1996 to $8.2 \mathrm{~L}$ in 2009 - a $13.0 \%$ increase in 13 years. ${ }^{4}$ The increase was most marked in regions where control systems have eroded. ${ }^{5}$

In addition, high-risk drinking is common and is highest among young adults. ${ }^{6}$ About one in five Canadians drink amounts that exceed recommended low-risk drinking guidelines and over $32 \%$ experienced problems in the past year due to drinking by others. ${ }^{6}$ In 2002 in Canada, there were an estimated 450000 dependent drinkers, 1.3 million high-risk drinkers ${ }^{7}$ and in excess of 8300 alcohol-caused deaths. ${ }^{8}$ And these figures do not reflect the much greater adverse impact of alcohol reflected in social problems, trauma and disability. ${ }^{2}$ Further, the impacts of rising consumption and high-risk

\section{- KeY POINTS}

- Alcohol is a substantial contributing cause of acute and chronic disease, trauma and social problems for many Canadians.

- With reduced controls and increasing consumption, the high level of harm from alcohol is expected to increase.

- A comprehensive public health response to reduce harm from alcohol requires combined population-level policies, improved access to services for high-risk drinkers, greater involvement by nongovernmental organizations and all public health sectors, and community-based leadership.

- A two-tiered response is recommended that, at the population level, targets pricing and restrictions on access, marketing and sponsorship and, at the front-line level, involves controls on drinking and driving, interventions by servers, public education and persuasion programs, and increased access to brief intervention and treatment. drinking also affect nondrinkers and create innocent victims. ${ }^{9}$

At the same time as consumption has been rising, controls have been eroded. As a result, the already high burden from alcohol is expected to increase if the status quo persists. Drawing on evaluations of programs and policies, this analysis outlines three main things that must be done to reduce the burden of alcohol to society, to highrisk drinkers and to those dependent on alcohol.

\section{A comprehensive response}

An effective response must be multidimensional, involving a combination of population-level policies, targeted interventions and special services for those who are high-risk drinkers or dependent on alcohol. Heavy episodic drinking is defined as the consumption of five or more drinks of standardized alcohol content $(13.45 \mathrm{~g}$ or $17.05 \mathrm{~mL}$ ethanol) on a single occasion at least monthly and is associated with an increased risk of trauma and chronic disease. ${ }^{10}$ Low-risk drinking is defined as no more than 14 drinks per week for men and 9 for women, with no more than 2 drinks per day. ${ }^{11}$

As defined in the Canadian Alcohol and Drug Use Monitoring Survey, ${ }^{12}$ alcohol-related harms can occur in the following eight domains: physical health; friendship and social life; financial position; home life and marriage; work, studies or employment opportunities; legal problems; difficulty learning; and housing problems. A risk analysis, which is based on reporting of at least one harm to self in the past year in any of these domains from one's own drinking, is presented in Table 1. Overall, $16.1 \%$ of respondents reported that alcohol had caused harm to them in their lifetime, and $6.5 \%$ reported that it had caused them harm in the past year.

A comprehensive response requires a crossdepartmental approach to setting policy on alcohol and a better balance by governments between the generation of revenue and the minimization of public health and safety impacts. Effective policies are needed to regulate access and overall 
consumption, and thereby reduce high-risk drinking linked to trauma, social problems and chronic diseases. ${ }^{10}$ At the same time, more focused interventions are also needed, and those already in place - such as evaluated server intervention programs and guidelines for alcohol marketing - should be strengthened. ${ }^{10,13,14}$

\section{Evidence-based interventions}

Interventions aimed at reducing and controlling the consumption of alcohol are also essential. Policies should be based on the evidence for their effectiveness and take into account sustainability, feasibility and scope of impact.

A two-tiered approach is proposed. The first tier of policies aims to reduce population-level damage from alcohol and reduce high-risk drinking in the future. The second tier of policies is oriented to specific drinking situations, risk behaviours, contexts or sectors of the population. Without effective action on the first tier, attempts to control the damage and costs from alcohol through second-tier interventions will, at best, be modestly effective.

\section{Tier 1: Population-level interventions}

\section{Alcohol pricing}

An international project linked with the $\mathrm{WHO}^{10}$ found that disincentive pricing of alcohol had the strongest empirical support and widest impact among more than 30 policies or interventions assessed. It leads to lower consumption and reductions in trauma, social problems and chronic disease associated with alcohol use. ${ }^{10}$ A metaanalysis published in 2009 and based on over 112 studies found strong support for this intervention. ${ }^{15}$ Pricing of alcoholic products needs to be structured so that prices increase as per cent alcohol content increases, needs to be charged at rates indexed to the cost of living, and needs to be prevented from falling below fixed minimum retail prices also indexed to the cost of living. ${ }^{14}$

\section{Controlling physical availability}

Substantial international research shows that high per capita or geographic density of outlets for purchasing alcohol as well as extended hours and days of sale are associated with high-risk drinking and alcohol-related problems..$^{10,13,16}$ It has also been shown that raising the minimum legal drinking age reduces sales of alcohol to minors and drinkingrelated problems. ${ }^{10}$ In light of increasing access to alcohol in recent years, including dramatic increases in some jurisdictions, ${ }^{5}$ a reduction in the physical availability of alcohol is important.

\section{Curtailing alcohol marketing}

A persistent challenge is the ubiquity, diversity and orientation of alcohol marketing and promotion, including advertising that is especially attractive to underage youth. ${ }^{17}$ Evidence indicates that exposing young people to alcohol marketing leads some to start drinking sooner and increases the amount consumed by those already drinking. ${ }^{10}$ In a recent US study, $24 \%$ of high school students reported consuming 4 or more drinks (reported by girls) or 5 or more drinks (reported by boys) within a couple of hours at least once in the past 30 days. $^{18}$

The extent of alcohol advertising, marketing and sponsorship by government-run alcohol retailing systems and alcohol producers is worri-

Table 1: Summary of drinking patterns and distribution of alcohol-related risk in Canada, 2009

\begin{tabular}{|c|c|c|c|c|}
\hline $\begin{array}{l}\text { Category based on } \\
\text { drinking pattern }\end{array}$ & $\begin{array}{l}\text { Definition (based on average } \\
\text { per-year consumption) }\end{array}$ & $\begin{array}{l}\% \text { of survey } \\
\text { respondents }\end{array}$ & $\begin{array}{l}\text { Estimated no. } \\
\text { of people }\end{array}$ & $\begin{array}{c}\text { Adjusted OR of reporting } \geq 1 \\
\text { harm to self from one's own } \\
\text { drinking in the past year }\end{array}$ \\
\hline Abstainer & No alcohol use in lifetime & 11.6 & \multirow[t]{2}{*}{6081000} & \multirow[t]{2}{*}{ NA } \\
\hline Former drinker & No alcohol use in past 12 months & 12.2 & & \\
\hline Current drinker & Consumed alcohol in the past 12 months & 76.5 & 19499750 & NA \\
\hline Light infrequent drinker & $\begin{array}{l}\text { Less than once per week and usually less } \\
\text { than five drinks per occasion }\end{array}$ & 36.1 & 9227000 & 1.0 (reference) \\
\hline Light frequent drinker & $\begin{array}{l}\text { Once or more per week and usually less } \\
\text { than five drinks per occasion }\end{array}$ & 31.3 & 8018000 & 2.18 \\
\hline Heavy infrequent drinker & $\begin{array}{l}\text { Less than once per week and usually five } \\
\text { or more drinks per occasion }\end{array}$ & 3.7 & 940750 & 4.37 \\
\hline Heavy frequent drinker & $\begin{array}{l}\text { Once or more per week and usually five } \\
\text { or more drinks per occasion }\end{array}$ & 5.1 & 1314000 & 11.84 \\
\hline
\end{tabular}


some and a likely contributor to the rising rate of consumption in the past 13 years. Therefore, policies to restrict the marketing of alcohol products through advertising, promotions and sponsorship, as has been done for tobacco, is recommended to control the harms from alcohol.

\section{Alcohol control systems}

A fourth intervention targets alcohol retailing arrangements. Government-run retailing systems, though not flawless, have a stronger potential than private systems to prevent service to minors and intoxicated patrons because staff are trained and the profit motive is not paramount with every sale. ${ }^{14}$ Further, restrictions on the per capita or geographic density of all alcohol outlets and disincentive pricing, which have been shown to be effective at reducing consumption, ${ }^{10,14,16}$ are easier to implement and maintain under a governmentrun system. There is international and national evidence in support of government-run alcohol retail systems as a means to reduce adverse consequences to public health and safety and to promote a public health approach to alcohol. ${ }^{5,10}$

A recent analysis of partial privatization of British Columbia's alcohol retailing system showed a greater increase in overall sales of alcohol in areas where there was a more dramatic increase in private-run outlets. ${ }^{5}$ However, the positive benefits of government-run retailing systems are greatly reduced if their primary mandate is to make money and they lose sight of public health and control obligations. Recognizing that many Canadian jurisdictions have committed in whole or part to a private distribution system, we strongly recommend that private systems be regulated and monitored to ensure that the interest of public health is pre-eminent and that, in light of international evidence of health risks associated with increased access to alcohol, ${ }^{10,13}$ further privatization does not occur.

\section{Tier 2: Focused policies and interventions}

\section{Drinking and driving}

Extensive evidence supports a number of interventions and policies for curtailing drinking and driving. ${ }^{10}$ These include sobriety checkpoints, random breath-testing, lower limits on legal blood alcohol concentration, "zero tolerance" rules for young drivers, administrative licence suspension and graduated licensing for novice drivers. ${ }^{10}$ Building on evidence-based interventions already in place, ${ }^{10,19}$ we recommend further steps to reduce the toll of drinking and driving on drivers, passengers and other victims by wider implementation of random breath testing and lower legal blood alcohol concentration limits.

\section{Changing the context of drinking}

Significant strides in this area have included use of training programs (e.g., Smart Serve Ontario) and house policies in the alcohol service industry related to responsible beverage service, training of staff and management to better handle aggression, enhanced enforcement of laws and other legal requirements for on-premise sales, and legal precedents regarding server liability. ${ }^{10} \mathrm{Nev}$ ertheless, given that many server training programs used in Canadian jurisdictions are not thoroughly evaluated, regular monitoring and quality control are needed.

\section{Education and persuasion}

Most school-based programs do not show a substantial impact on drinking behaviour or damage from alcohol, ${ }^{10,20}$ although some intensive programs aimed at university students are beginning to show promise. ${ }^{10}$ Resources should be redirected to those programs with a demonstrated positive impact. At the same time, education and persuasion techniques should be oriented toward increasing awareness of population-level damage from alcohol and should provide guidance on the roles that citizens can play in reducing the harm from alcohol in their community. ${ }^{20}$ From a consumer perspective, there is also a right-to-know aspect to the health effects of alcohol, and so we welcome the development of national guidelines for low-risk drinking among Canadians ${ }^{21}$ and the implementation of those guidelines in combination with effective control measures. ${ }^{15,16}$

\section{Increased access to brief interventions}

We also recommend increasing access to brief interventions so that all adult at-risk drinkers potentially can benefit. Brief interventions are intended for those who are at risk but who do not meet the criteria of alcohol use disorders, whereas early intervention and treatment is considered appropriate for the latter group. Brief interventions involve a combination of several steps, as noted in the Clinical Guide for Reducing Alcohol Risks and Harms ${ }^{22}$ and outlined in a recent systematic review. ${ }^{23}$

In addition to brief interventions that are administered by health professionals, evaluated online self-help versions are also available. ${ }^{24}$ These interventions can help reduce high risk drinking ${ }^{23}$ and are projected to have a substantial public health benefit in reducing demand on health care and attendant costs..$^{13}$ Table $2^{10,13-16,19}$ $22,25-29$ provides an overview of the policies noted above, organized into two tiers.

There have been several initiatives to assess the impact of interventions and policies. ${ }^{13,25} \mathrm{~A}$ recent analysis by Anderson and colleagues ${ }^{13}$ esti- 
mated that the cost in the Americas was US\$2.35 per person to implement a combined strategy focusing on brief advice, random breath-testing, reduced access to alcohol, a ban on advertising of alcohol, a 50\% increase in tax on alcoholic beverages and enforcement to reduce unrecorded consumption. By contrast, the cost per disabilityadjusted life-year savings was US\$691.

\section{A comprehensive approach}

Effectively tackling major health and social problems related to alcohol consumption requires a combination of leadership, persistence, resources and a broad base of support ${ }^{26,27}$ at national, regional and local levels and should include communitybased interventions that address injuries or vio-

Table 2: A two-tiered, multidimensional strategy to reduce the toll of alcohol-related harms in Canada

\begin{tabular}{|c|c|c|c|}
\hline Tier & Dimension & Intervention & Recent examples \\
\hline 1. & $\begin{array}{l}\text { Pricing and } \\
\text { taxation }^{10,13,15,25,27-29}\end{array}$ & $\begin{array}{l}\text { - Impose minimum prices in all provinces and } \\
\text { territories for both retail establishments and } \\
\text { licensed premises for on-premise sales }{ }^{13,28} \\
\text { - Index alcohol prices to cost of living } \\
\text { - } \text { Eliminate discount pricing }^{27} \\
\text { - Apply excise tax graduated by volume of } \\
\text { ethanol }{ }^{10,27}\end{array}$ & $\begin{array}{l}\text { Indexed minimum pricing for retail } \\
\text { establishments under legislation removing } \\
\text { administrative discretion (Ontario); automatic } \\
\text { indexing of prices for beer (Quebec); } \\
\text { implementation in April } 2010 \text { of a } \\
\text { comprehensive system of minimum pricing } \\
\text { (Saskatchewan); minimum prices imposed on } \\
\text { licensed premises (Nova Scotia, Alberta) }\end{array}$ \\
\hline & $\begin{array}{l}\text { Physical availability of } \\
\text { alcohol }\end{array}$ & $\begin{array}{l}\text { - Reduce density of outlets and hours of sale }{ }^{10,13,16,25} \\
\text { - Assess impact of outlet concentration in } \\
\text { entertainment districts }\end{array}$ & $\begin{array}{l}\text { Substantial increases in geographic density of } \\
\text { various privately run liquor stores (British } \\
\text { Columbia) }\end{array}$ \\
\hline & $\begin{array}{l}\text { Marketing, advertising } \\
\text { and sponsorship }{ }^{10,13,27}\end{array}$ & $\begin{array}{l}\text { - Eliminate marketing of alcohol oriented to } \\
\text { youth } \\
\text { - Reduce marketing by government liquor boards } \\
\text { and agencies and by the private sector } \\
\text { - Implement effective, efficient interventions for } \\
\text { breaches of advertising policy } \\
\text { - Limit or ban alcohol industry sponsorship of } \\
\text { cultural or sporting events }\end{array}$ & $\begin{array}{l}\text { Extensive advertising (in various provinces) of } \\
\text { alcoholic beverages by alcohol producers, } \\
\text { private retailers and government liquor boards } \\
\text { or commissions via electronic media, special } \\
\text { magazines, newspaper inserts and on public } \\
\text { transit vehicles }\end{array}$ \\
\hline & Control system ${ }^{10,13,25,28}$ & $\begin{array}{l}\text { - Impose moratorium on partial or full } \\
\text { privatization of off-premise alcohol retailing } \\
\text { - Enhance emphasis on a control mandate for } \\
\text { government liquor control agencies and } \\
\text { boards }^{10,13,26}\end{array}$ & $\begin{array}{l}\text { Only Alberta has fully privatized retail alcohol } \\
\text { sales (for "off premise" consumption). Most } \\
\text { other jurisdictions (e.g., Quebec, British } \\
\text { Columbia) have combined public-private } \\
\text { systems. New Brunswick, Prince Edward Island } \\
\text { and Northwest Territories have an exclusive } \\
\text { government monopoly in the organization of } \\
\text { retail alcohol sales. }\end{array}$ \\
\hline 2. & $\begin{array}{l}\text { Drinking-and-driving } \\
\text { countermeasures }{ }^{10,13,19,27}\end{array}$ & $\begin{array}{l}\text { - Implement strategies recommended by Mothers } \\
\text { Against Drunk Driving in all provinces and } \\
\text { territories } \\
\text { - Increase resources for random roadside spot } \\
\text { checks } \\
\text { - Implement a legal BAC limit of } 0.05^{10,25}\end{array}$ & $\begin{array}{l}\text { Biannual rating of provinces and territories } \\
\text { has contributed to concerted efforts to } \\
\text { implement effective interventions. }{ }^{19} \text { British } \\
\text { Columbia has enhanced penalties for } 0.05 \text { BAC } \\
\text { infractions, including repeat offences. }\end{array}$ \\
\hline & Minimum age ${ }^{10,28}$ & $\begin{array}{l}\text { - Raise minimum legal age for purchasing alcohol } \\
\text { to } 19 \text { in all provinces and territories }\end{array}$ & $\begin{array}{l}\text { Legal purchase age is } 18 \text { in Alberta, Manitoba } \\
\text { and Quebec, and is } 19 \text { in all other jurisdictions. }\end{array}$ \\
\hline & $\begin{array}{l}\text { Altering the context of } \\
\text { drinking }\end{array}$ & $\begin{array}{l}\text { - Increase ratio of liquor inspectors to outlets } \\
\text { - Implement "Safer Bars" and other evidence- } \\
\text { based interventions }{ }^{25,27} \\
\text { - Use only evaluated server training programs in } \\
\text { all provinces and territories }\end{array}$ & $\begin{array}{l}\text { "Safer Bars" is being implemented in Alberta } \\
\text { after successful trial in Toronto. }\end{array}$ \\
\hline & $\begin{array}{l}\text { Education and } \\
\text { persuasion }^{10,13,20,28,29}\end{array}$ & $\begin{array}{l}\text { - Orient resources to school and college-based } \\
\text { programs with proven positive impact on } \\
\text { drinking or drinking-related harms }{ }^{10,20} \\
\text { - Educate policy-makers about evidence of } \\
\text { damage and costs from alcohol and high-impact } \\
\text { interventions, and enhance role of public health } \\
\text { specialists in alcohol policy deliberations } \mathrm{s}^{20}\end{array}$ & $\begin{array}{l}\text { National low-risk drinking guidelines were } \\
\text { finalized under the National Alcohol } \\
\text { Strategy. }\end{array}$ \\
\hline & $\begin{array}{l}\text { Screening, brief } \\
\text { intervention and } \\
\text { referral } \\
\text { 10, 13,21,22,25,29 }^{-1}\end{array}$ & $\begin{array}{l}\text { - Increase access to screening and brief } \\
\text { interventions via clinics, university health care } \\
\text { services and hospitals and online }{ }^{10,25} \\
\text { - Orient resources to treatment interventions with } \\
\text { evidence of positive impact }{ }^{10,13}\end{array}$ & $\begin{array}{l}\text { An online resource was developed (also under } \\
\text { the National Alcohol Strategy) to support } \\
\text { health professionals in delivering brief } \\
\text { assessment and intervention. }\end{array}$ \\
\hline
\end{tabular}


lence. ${ }^{10,27}$ Physicians and other public health professionals can raise public awareness in their communities of the problems associated with alcohol sales and distribution (e.g., service to minors and intoxicated patrons) and facilitate support for initiatives at the provincial or territorial level.

However, alcohol is often not on the radar as a major public health issue at the broader community level. ${ }^{26}$ Chronic disease alliances and charities are encouraged to become international leaders on this topic by paying attention to alcohol consumption as a public health issue, engaging with alcohol specialists, enhancing their capacity to deal with this topic and fostering prevention campaigns that focus on alcohol-related issues.

Robust interventions require coordinated multisectoral action. Whereas physicians and other health care professionals have a key role to play in many interventions, other strategies require, in addition, the expertise of liquor inspectors, law enforcement personnel or municipal officials and the cooperation of alcohol retailers and licensing agencies. ${ }^{10,14,26}$ Skill-building and training are essential components and include efforts to increase knowledge, not only about the damage from alcohol and the risks involved, but also about which interventions are feasible at local and provincial levels and how to initiate change. ${ }^{26}$

There have been several promising developments. In 2007, a Canadian National Alcohol Strategy ${ }^{28}$ developed by the Canadian Centre on Substance Abuse and other partners put forward 41 recommendations that are being implemented. Recent reports on alcohol-related policy from Nova Scotia, ${ }^{30}$ British Columbia ${ }^{14}$ and Quebec ${ }^{31}$ have recommended effective interventions. Outside of our borders, the British Medical Association's strong interest in reducing the burden from alcohol in Britain $^{32}$ provides a timely model for the Canadian Medical Association to consider. The World Health Organization's global strategy to reduce the harmful use of alcohol, approved by the General Assembly in May 2010, ${ }^{29}$ recommends a range of the universal and targeted interventions discussed here, including those that address pricing, physical availability of alcohol, drinking and driving, and brief interventions.

There is strong epidemiological evidence to support engagement on this health issue ${ }^{2}$ and there are specific evidence-based interventions that can be promoted, implemented and monitored. . $^{10,13,27}$ Governments, public health agencies and the medical community are urged to be proactive on this issue and encourage comprehensive approaches and community support for effective action.

Whether the next decade will see a further increase in alcohol consumption, high-risk drinking and damage from alcohol will depend largely on whether the public health community and those responsible for alcohol control step into a leadership role, draw attention to this issue and take the steps needed to reduce the health and safety burden in Canadian communities. Are they up to the task?

\section{References}

1. World Health Organization. Global health risks. Mortality and burden of disease attributable to selected major risks. Geneva: The Organization; 2009. Available: www.who.int/healthinfo /global_burden_disease/GlobalHealthRisks_report_full.pdf (accessed 2011 Jan. 25)

2. Rehm J, Mathers C, Popova S, et al. Alcohol and global health 1. Global burden of disease and injury and economic cost attributable to alcohol use and alcohol-use disorders. Lancet 2009; 373:2223-33.

3. Rehm J, Baliunas D, Brochu S, et al. The costs of substance abuse in Canada 2002. Ottawa (ON): Canadian Centre on Substance Abuse; 2006.

4. Volume of sales of alcoholic beverages in litres of absolute alcohol and per capita 15 years and over, fiscal years ended March 31, annual. CANSIM Table 183-0019. Ottawa (ON): Statistics Canada; 2009.

5. Stockwell T, Zhao J, Macdonald S, et al. Changes in per capita alcohol sales during the partial privatization of British Columbia's retail alcohol monopoly 2003-2008: a multi-level local area analysis. Addiction 2009; 104:1827-36.

6. Adlaf E, Begin P, Sawka A, editors. Canadian Addiction Survey (CAS): a national survey of Canadians' use of alcohol and other drugs. Prevalence of use and related harms: detailed report. Ottawa (ON): Canadian Centre on Substance Abuse; 2005. p. $33-47$

7. Tjepkema M. Alcohol and illicit drug dependence. Ottawa $(\mathrm{ON})$ : Statistics Canada; 2004. Available: www.statcan.gc.ca/pub /82-003-s/2004000/pdf/7447-eng.pdf (accessed 2010 Jan. 11).

8. Stockwell T, Chikritzhs T, Bostrom A, et al. Alcohol-caused mortality in Australia and Canada: scenario analyses using different assumptions about cardiac benefit. J Stud Alcohol Drugs 2007;68:345-52.

9. Giesbrecht N, Cukier S, Steeves D. Collateral damage from alcohol: implications of 'second-hand effects of drinking' for populations and health priorities. Addiction 2010;105:1323-5.

10. Babor T, Caetano R, Casswell S, et al. Alcohol: no ordinary commodity. Research and public policy. Revised edition. Oxford (UK): Oxford University Press; 2010.

11. Centre for Addiction and Mental Health. Low risk drinking guidelines Toronto. Toronto (ON): The Centre; 2009. Available: www .camh.net/About_Addiction_Mental_Health/Drug_and_Addiction _Information/low_risk_drinking_guidelines.html (accessed 2010 Nov. 5).

12. Canadian Alcohol and Drug Use Monitoring Survey. Ottawa $(\mathrm{ON})$ : Health Canada; 2009. Available: www.hc-sc.gc.ca/hc-ps /drugs-drogues/stat/_2009/summary-sommaire-eng.php\#intro (accessed 2011 Jan. 17).

13. Anderson P, Chisholm D, Fuhr D. Alcohol and global health 2 : effectiveness and cost-effectiveness of policies and programmes to reduce the harm caused by alcohol. Lancet 2009;373:2234-46.

14. A public health approach to alcohol policy: an updated report from the Provincial Health Officer. Victoria (BC): Office of the BC Provincial Health Officer; 2008.

15. Wagenaar AC, Salois M, Komro K. Effects of beverage alcohol price and tax levels on drinking: a meta-analysis of 1003 estimates from 112 studies. Addiction 2009;104:179-90.

16. Popova S, Giesbrecht N, Bekmuradov D, et al. Hours and days of sale and density of alcohol outlets: Impacts of alcohol consumption and damage: a systematic review. Alcohol Alcohol 2009; 44:500-16.

17. Jernigan D.H. The extent of global alcohol marketing and its impact on youth. Contemp Drug Probl 2010;37:57-90

18. Centers for Disease Control and Prevention. Vital signs: binge drinking among high school students and adults - United States, 2009. MMWR Morb Mortal Wkly Rep 2009;59:1274-9.

19. Rating the provinces and territories: the 2009 report. Oakville (ON): Mothers Against Drunk Driving; 2009. Available: http ://madd.ca/english/research/rtp2009.pdf (accessed 2010 June 11).

20. Giesbrecht N. Reducing alcohol-related damage in populations: rethinking the roles of education and persuasion interventions. Addiction 2007;102:1345-9.

21. Butt P, Beirness D, Cesa F, et al. Alcohol and health in Canada: a summary of evidence and guidelines for low risk drinking. Ottawa (ON): Canadian Centre on Substance Abuse. In press. 
22. College of Family Physicians. Clinical guide for reducing alcohol risks and harm. (Protoype being developed for family physicians and other health professionals). Available: http://seapath.org / (accessed 2011 Jan. 25)

23. Kaner EFS, Dickinson HO, Beyer F, et al. The effectiveness of brief alcohol interventions in primary care settings: a systematic review. Drug Alcohol Rev 2009;28:301-23.

24. Cunningham JA, Wild TC, Cordingley J, et al. A randomized controlled trial of an internet-based intervention for alcohol abuser. Addiction 2009;104:2023-32.

25. Rehm J, Gnam W, Popova S, et al. Avoidable cost of alcohol abuse in Canada 2002. Toronto (ON): Centre for Addiction and Mental Health; 2008.

26. Giesbrecht N, Room R, Demers A, et al. Alcohol policies: Is there a future for public health considerations in a commerciallyoriented environment? In: Giesbrecht N, Demers A, Ogborne A, editors. Sober reflections: commerce, public health, and the evolution of alcohol policy in Canada, 1980-2000. Montréal (QC): McGill-Queen's University Press; 2006. p. 289-329.

27. Casswell S, Thamarangsi T. Alcohol and global health 3 . Reducing harm from alcohol: call to action. Lancet 2009;373:2247-57.

28. National Alcohol Strategy Working Group. Reducing alcohol related harm in Canada: toward a culture of moderation. Recommendations for a national alcohol strategy. Ottawa (ON): The Group; 2007.

29. World Health Organization news release. Call for action to reduce the harmful use of alcohol. Geneva: The Organization; 2010. Available: www.who.int/mediacentre/news/releases/2010 /alcohol_20100521/en/print.html (accessed 2010 June 11).

30. Changing the culture of alcohol use in Nova Scotia. An alcohol strategy to prevent and reduce the burden of alcohol-related harm in Nova Scotia. Halifax (NS): Nova Scotia Department of Health Promotion and Protection; 2007.

31. April N, Begin C, Morin R. La consommation d'alcool et la sante publique au quebec: direction du developpement des individus et des communautés. Montréal (QC): Institut national de santé publique du québec; 2010.

32. British Medical Association Science and Education Department Alcohol misuse: tackling the UK epidemic. London (UK): British Medical Association Board of Science; 2008.

Competing interests: Timothy Stockwell has served as a paid consultant for the Canadian Centre on Substance Abuse, the National Drug Research Institute and the School of Public Health, University of Sheffield. He has received monetary compensation for travel expenses from the Thailand National Centre for Alcohol Studies for a keynote address in Bangkok, from the Swedish Institute for Public Health for workshop participation, from Health Canada for attendance on a national drug surveillance advisory committee, and from the US National Alcoholic Beverage Control Association for attendance at an international meeting on government monopoly of alcohol sales. No competing interests for Norman Giesbrecht, Perry Kendall, Robert Strang or Gerald Thomas.

Affiliations: From the Social and Epidemiological Research Department (Giesbrecht), Centre for Addiction and Mental Health, Toronto, Ont.; the Centre for Addictions Research of British Columbia (Stockwell), University of Victoria, Victoria, BC; the British Columbia Ministry of Health (Kendall), Victoria, BC; the Nova Scotia Department of Health and Wellness (Strang), Halifax, NS; and the Centre for Addictions Research of British Columbia (Thomas), Victoria, BC

Contributors: All of the authors contributed to the conception of the article. Norman Giesbrecht drafted the manuscript. All of the authors were involved in the revision of the manuscript, and all of them approved the final version submitted for publication.

Funding: Norman Giesbrecht is an employee of the Centre for Addiction and Mental Health, Toronto, which receives funding for the salaries of its scientists from the Ontario Ministry of Health and Long-Term Care.

Acknowledgements: The authors thank Denise De Pape for feedback on an earlier draft and Chris Davis for his contribution to the analysis presented in Table 1.

\section{HYDROMORPH Contin'q12h}

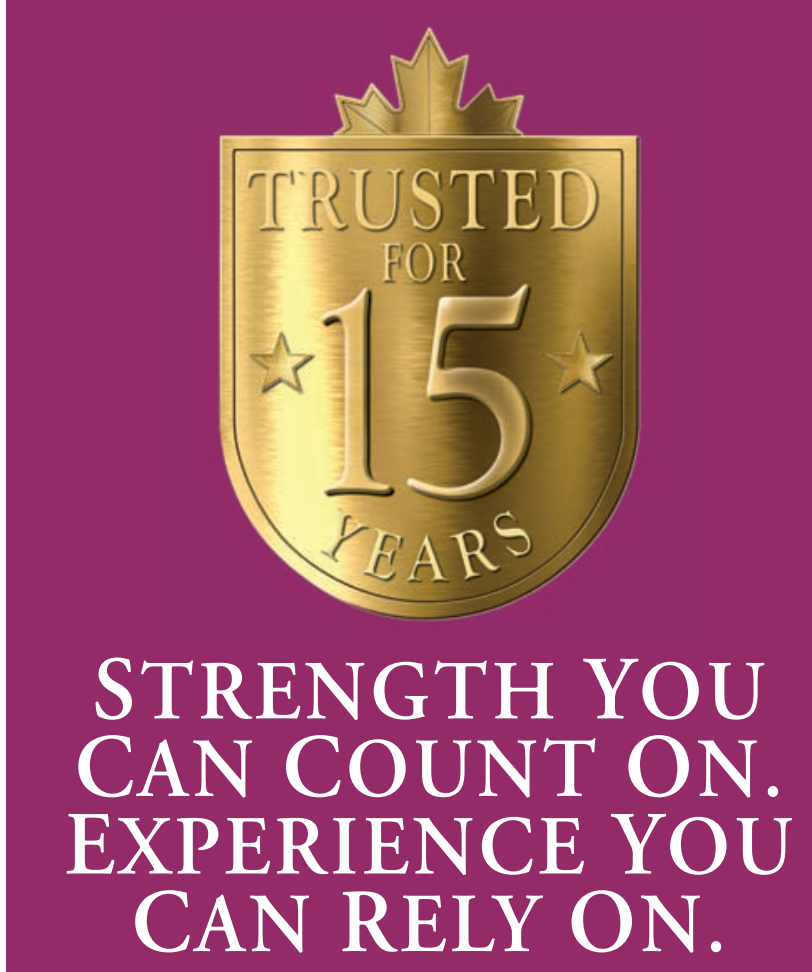

Hydromorph Contin ${ }^{\circledR}$ is indicated for the relief of severe chronic pain requiring the prolonged use of an oral opioid preparation.

Side effects are similar to other opioid analgesics. The most frequently observed are asthenic conditions, confusion, constipation, dizziness, lightheadedness, nausea, sedation, sweating and vomiting. Dosage limitations may be imposed by adverse effect. If they occur, please refer to prescribing information.

Warning: Opioid analgesics should be prescribed and handled with a high degree of caution appropriate to the use of a drug with strong abuse potential. Patients should be cautioned not to consume alcohol while taking Hydromorph Contin ${ }^{\circledR}$, as it may increase the chance of experiencing dangerous side effects. Hydromorph Contin ${ }^{\circledR} 18 \mathrm{mg}$ capsules and higher are for use in opioid tolerant patients only. There is a potential for fatal respiratory depression in patients not previously exposed to similar equianalgesic doses of an opioid analgesic. Hydromorph Contin ${ }^{\circledR}$ capsules or capsule beads should not be chewed, crushed or dissolved since this can lead to rapid release and absorption of a potentially fatal dose of hydromorphone. Product monograph available on request.

Hydromorph Contin ${ }^{\circledR}$ capsule beads may be sprinkled on cold, soft food.

\section{'HYDROMORPH Contin'q12h}

A trusted choice for severe chronic pain

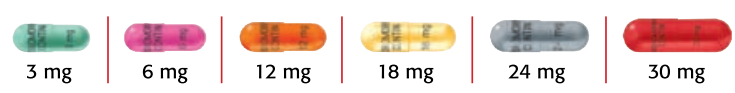

Initiation at $3 \mathrm{mg} \mathrm{q} 12 \mathrm{~h}$ or calculate the approximate daily oral hydromorphone dosage that should provide equivalent analgesia. See Product Monograph Table 1, Opioid Analgesics: Approximate Analgesic Equivalences. 